Figueras Ferrer, Eva.

Profesora titular de la Universidad de Barcelona, Departamento de Pintura.

\author{
Rosado Rodrigo, Pilar. \\ Investigadora de la Universidad de Barcelona y miembro del BRAC Barcelona Research Art Creation.
}

\title{
Street Art en acción: del graffiti artesanal al soporte digital.
}

\author{
TIPO DE TRABAJO \\ Comunicación virtual. \\ PALABRAS CLAVE \\ Graffiti animado, graffiti digital, graffiti performance, graffiti interactivo, Street Art.
}

KEY WORDS

Animated graffiti, digital graffiti, graffiti performance, interactive graffiti, Street Art.

\section{RESUMEN}

El Graffiti incluye diferentes modalidades que van desde la acción directa -el Writing, el Subway Art, el Hip Hop Graffiti- al graffiti indirecto promulgado dentro del propio ámbito artístico como es el Stencil Art, pasando por las nuevas etiquetas de Postgraffiti, Neograffiti, Street Art o Arte urbano de finales de los 90, hasta el graffiti animado actual, quizás último eslabón de la cadena, donde la artesanía encuentra un aliado digital. Analizaremos la obra de algunos artistas e ilustradores que, no conformes solamente con pintar paredes, han dedicado mucho tiempo y esfuerzo a realizar animaciones 'stock motion' con graffiti. Tal es el caso de los graffiti animados de Blu, o los Gif animados de Insa, que sólo se pueden ver en la Web. Otros artistas conciben el graffiti como parte integrante de la obra que posteriormente será visionada en un soporte diferente al muro donde fue gestado. Son un ejemplo las fotografías de Alexander Orion, autor también de una performance de 'limpieza urbana' en San Paulo, o los graffiti interactivos de Sweza, en los que se requiere la interacción del peatón provisto de un lector $Q R$ de un smartphone para visualizar la obra que nos propone el artista. Terminaremos con una reflexión acerca de las connotaciones estéticas y conceptuales de los graffiti artesanales y los graffiti animados de última generación.

\section{ABSTRACT}

Graffiti includes different modalities which go from direct action -"Writing", "Subway Art", "Hip Hop Graffiti"- to indirect graffiti, promulgated on its own artistic field as "Stencil Art", going through the new labels of "Postgraffiti", "Neografitti", "Street Art" or "Urban Art" of the end of the 90s, until the current animated graffiti, perhaps the last link of the chain, where craftwork finds a digital ally. We will analyse the work of some artists and illustrators who, not satisfied with only painting walls, have dedicated a long time and effort to create animations "stock motion" with graffiti. This is the case of Blue's animated graffiti, or Insa's animated Gifs, which can only be visualized in the Web. Other artists conceive the graffiti as an integral part of the work which afterwards will be envisioned in a different support from the wall in which it was gestated. As examples of it we find the photographs of Alexander Orion, also author of a performance of "urban cleaning" in Sao Paulo, or the interactive graffiti of Sweza, in which the interaction of a pedestrian provided with a QR code of a Smartphone is required to visualize the work the artist proposes. We will end up with a critical reflection around the esthetical and conceptual connotations of the handcrafted graffiti and the animated graffiti of last generation. 


\section{CONTENIDO}

\section{Introducción}

Desde la época del modelo neoyorquino basado en la distorsión de letras de finales de los años 70, han surgido tantos estilos nuevos de graffiti que las fronteras entre ellos se han ido desdibujando. Hoy en día la cultura se ha ampliado: Se exponen nuevas formas y han comenzado a proliferar personajes del cómic, figuras de gran fotorrealismo, símbolos y abstracciones - logos e iconos se especializan en emblemas y figuras llamativas y sintéticas.

Aunque el bote de spray sigue siendo la herramienta fundamental del graffitero, la variedad de material disponible - tiza al aceite, aerógrafo, pinturas al aceite o acrílicas, pegatinas... - es muy extensa y ha ampliado el abanico artístico. Esta evolución ha supuesto la revisión de las valoraciones culturales sobre el graffiti. Incluso se ha planteado la estimación de cualidades estéticas y se ha gestado un movimiento artístico o "para-artístico" (Figueroa-Saavedra, 2007:120): desde la acción directa del Writing, el Subway Art y el Hip Hop Graffiti, al graffiti indirecto promulgado dentro del propio ámbito artístico como es el Stencil Art - divulgado dentro del propio ámbito artístico, dada su focalización en los aspectos más relacionados con lo conceptual, lo artístico y lo semiótico que dan la impresión de ser una producción 'ordenada'.

A finales el los 90 e inicios de la primera década del siglo XXI, proliferan nuevos agentes del mundo del arte que toman las calles como laboratorios de creatividad o como escenarios principales de innovaciones y experimentos de primera mano. De este modo se produce una efervescencia creativa en el espacio público, desde la confluencia de muy distinto perfil u origen, sugiriendo etiquetas como Postgraffiti, Neograffiti, Street Poetry o Arte Urbano ${ }^{1}$, caracterizados por aproximaciones formales i técnicas innovadoras que van más allá de las concepciones tradicionales del clásico graffiti. Pensamos que ante esta proliferación de denominaciones, la nominación Street Art es suficientemente globalizadora como para referirse a todas ellas y considerarla un término genérico propicio para referirnos a todas las excepciones que nos encontremos a lo largo de este artículo.

Las nuevas condiciones técnicas, tipológicas, estilísticas e ideológicas, hacen del Street Art un espacio de creación, observación, reivindicación, reflexión y teorización. En definitiva, el Street Art propicia un escaparate de debate en lo cultural, social y político en el que la mayoría podemos sentirnos cómodos e identificados.

El graffiti animado es quizás uno de los máximos exponentes del Street Art de los cinco continentes que reúne en una obra de arte el proceso artesanal ejecutado a pie de calle con el tecnológico-digital visible en WWW (World Wide Web) o Web a nivel mundial.

\section{Graffiti animado versus graffiti convencional}

El graffiti animado es un graffiti que sólo puede visionarse en un soporte digital, generalmente Web. A diferencia del graffiti convencional, el graffiti animado es el resultado de un proyecto de una cierta envergadura, que requiere de un equipo técnico y humano para su realización. En él se aúnan procesos artesanales con procesos tecnológicos de última generación para culminar en un trabajo artístico en el ciberespacio, plataforma de exposición y contemplación de la obra finalizada.

Creemos que definir y delimitar el graffiti animado es difícil y arriesgado, aunque podamos establecer unos parámetros, como pueden ser, a modo de ejemplo, la calle como plataforma de acción, la confluencia de trabajo artesanal (pintura, dibujo...) con lo tecnológicodigital, la contemplación del graffiti en el ciberespacio... En este artículo hemos visitado algunos graffiti animados de artistas e ilustradores y hemos llegado a la conclusión que existen tantas modalidades y variantes como acciones creativas.

\subsection{Antecedentes del graffiti animado}

Para hablar del proceso de realización del graffiti animado nos tenemos que remontar a la primera mitad del siglo XIX con el zoótropo ${ }^{2}$ o daedaleum (fig.1), conocido también como tambor mágico, rueda de la vida o rueda del diablo. Fue un juguete óptico basado en el fenómeno de la persistencia retiniana para crear la ilusión de movimiento ${ }^{3} y$, consecuentemente, fue una inspiración para la creación de lo que hoy conocemos como cine ya que es el mismo principio, una sucesión de imágenes que cuentan una historia.

El graffiti animado no es el único procedimiento dentro de los graffiti que utiliza recursos de animación cinematográficos. Encontramos artistas que aplican en el muro la técnica basada en los dibujos dispuestos en tiras animadas muy parecidos a los que se disponen sobre el tambor de zoótropo, que al girar dan la ilusión de movimiento. 


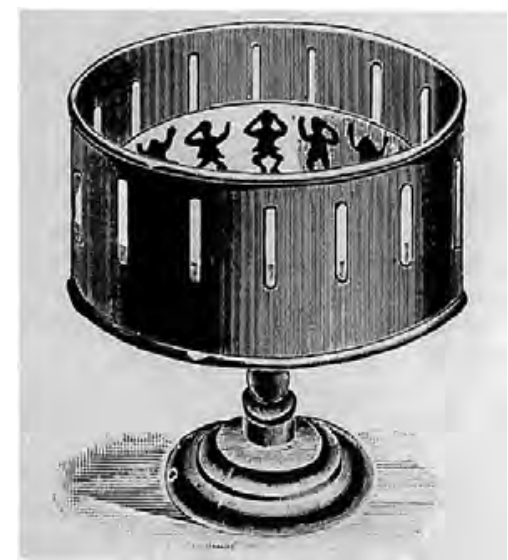

Fig.1 Zoótropo

A modo de ejemplo, comparemos los murales In Between ${ }^{4}$ (Orestad, Copenhage, 2013) (fig.2a y 2b) o Layers (2011) de Hyuro - artista argentina afincada en España - o los de Escif (fig.3a y 3b) - artista callejero de Valencia - con las tiras animadas destinadas al zoótropo (fig.4a y $4 b)$ :

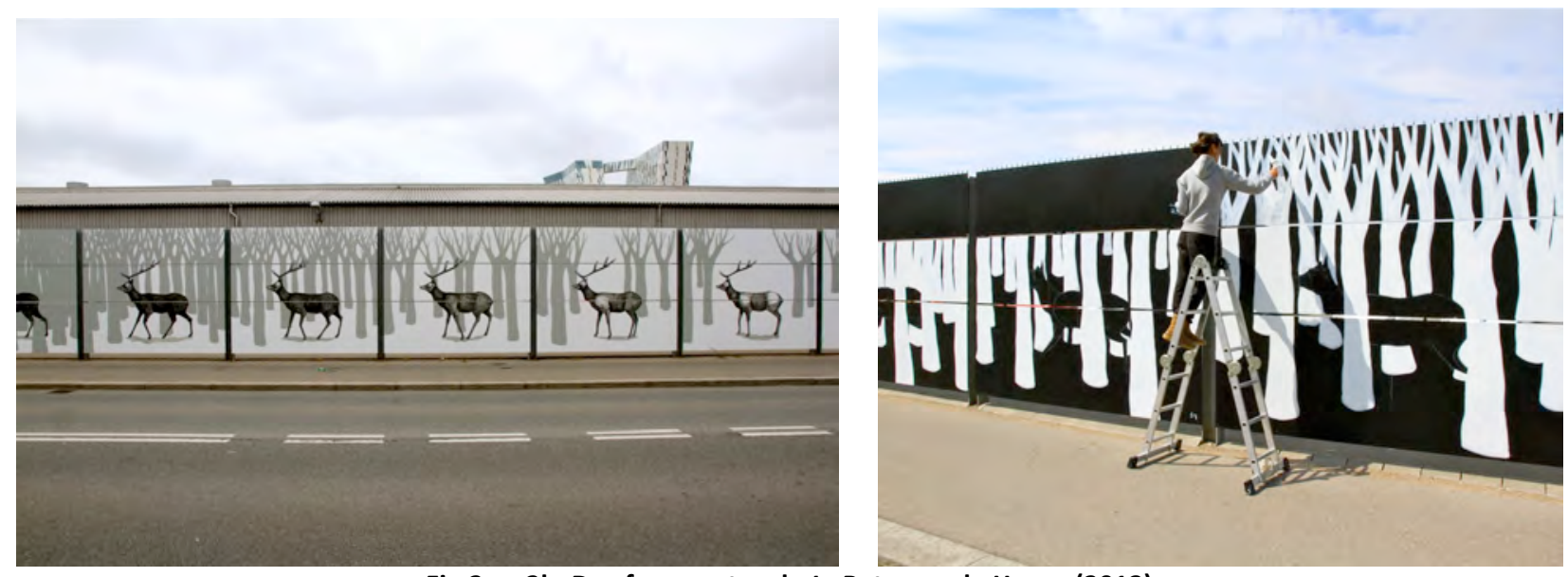

Fig.2a y 2b. Dos fragmentos de In Between de Hyuro (2013)
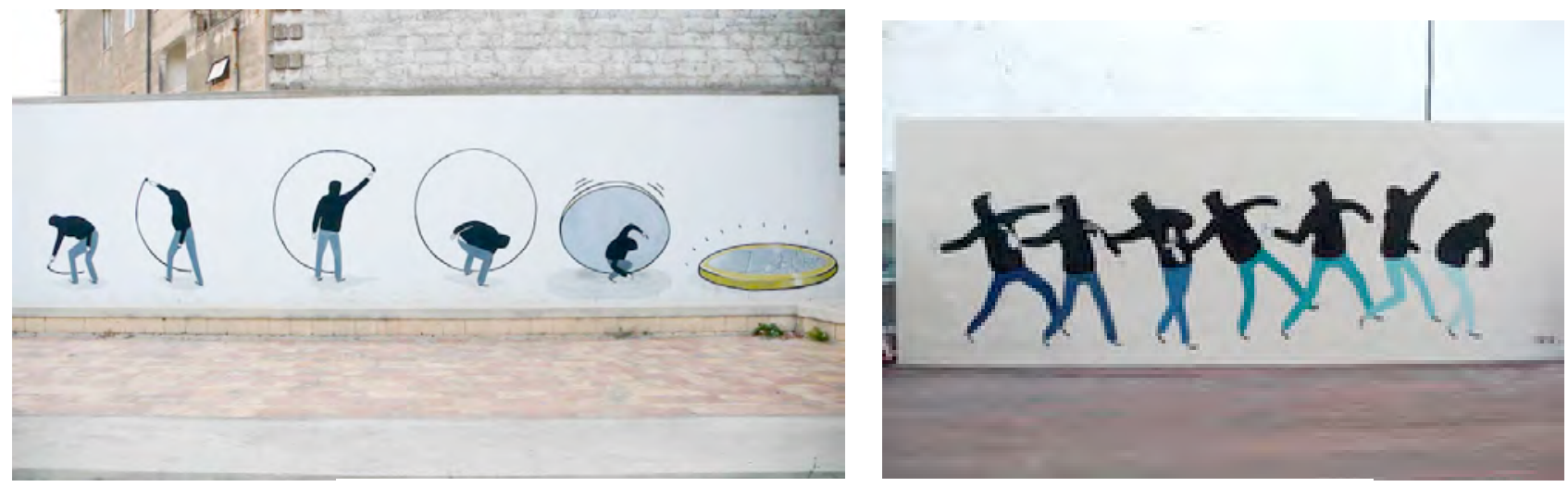

Fig.3a Escif, Fame Festival (Grottaglie, Italia, 2010), 3b. Vandalism Choreography (Valencia, 2009 

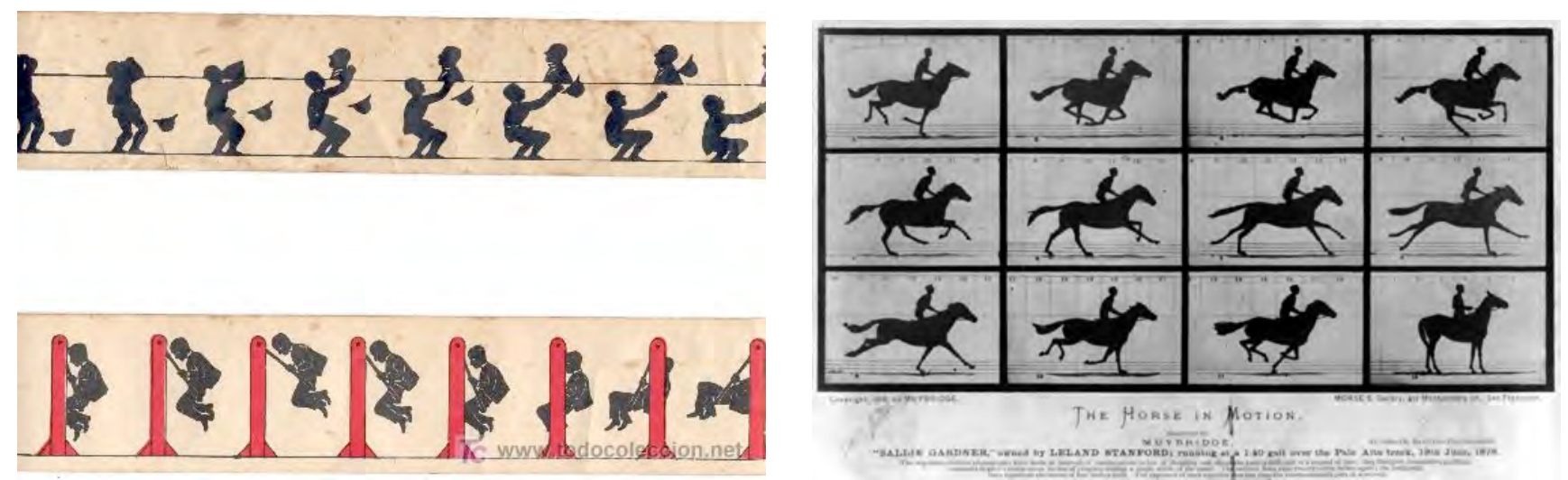

Fig.4a y 4b. Imágenes de tiras de dibujos para zoótropo

Las imágenes de Hyuro y de Escif, al igual que las tiras animadas del juguete, despliegan una acción que realiza un personaje dentro de un plano, el muro o el papel. En el caso del alce de Hyuro, por ejemplo, el automóvil circulando por la carretera ejerce la función del zoótropo.

\subsection{El graffiti animado: convergencia del proceso artesanal y las nuevas tecnologías}

Al realizar un graffiti animado el artista (o el equipo colaborador) se aventura a pintar en un muro urbano una serie de fotogramas que son digitalizados uno a uno para su posterior edición animada. Evidentemente estamos hablando de un trabajo de una cierta envergadura, ya que se trata de una pintura mural de dimensiones considerables que se genera a partir de muchos dibujos consecutivos, borrando y volviendo a pintar el muro en cada toma de movimiento. A diferencia de los dibujos animados tradicionales en los que se utilizan diferentes soportes de papel para proyectar los dibujos del movimiento, en el graffiti animado se parte de un único soporte que habitualmente suele ser una pared, aunque también puede darse el caso, como los graffiti animados de Blu, de que la animación se desplace por una serie de fachadas, por un puente, por la calzada, etc. siguiendo un recorrido en un soporte expandido del casco urbano. Teniendo en cuenta la necesidad de unos 24 fotogramas para causar la sensación de movimiento, podemos hacernos una idea aproximada del trabajo requerido para animar una imagen de dimensiones murales, encima de un soporte no siempre liso y regular, y que para narrar la secuencia de movimiento el artista tiene que modificar continuamente el dibujo sobre el mismo espacio físico. Este proceso de dibujar, borrar parcialmente, volver a dibujar... es muy laborioso y artesanal, en el sentido tradicional del término - manual en oposición a seriado o industrial.

El graffiti animado si bien tiene esta componente manual, no tendría razón de ser sin la intervención de la tecnología digital. Cada dibujo es un fotograma que contribuirá a narrar la secuencia en movimiento que nos proporcionará la animación. El graffitero no deja en la pared una intervención en el espacio urbano para ser contemplada por los transeúntes, sino que la intervención urbana será visualizada en forma de animación, generalmente creada a partir de la técnica stop-motion ${ }^{5}$ y colgada en la red.

\section{Tipologías de graffiti animado}

Dentro de los graffiti animados que sólo pueden ser visionados en soporte digital (generalmente la Web) podemos encontrar tantas variantes como artistas e ilustradores lo practican. Tal es el caso de los graffiti animados de Blu o de Saner, o los GIF animados de Insa, el speed-painting de Denny Dent o los graffiti interactivos con código QR de Sweza, entre otras acciones que bien podemos denominar graffiti animado.

\subsection{Los graffiti fílmico-narrativos de Blu}

No cabe duda que en la trayectoria artística del argentino Blu el graffiti es uno de sus medios de expresión. Blu es uno de los creadores gráficos más vanguardistas e innovadores que han contribuido a dar forma a esta nueva tendencia creativa, evidenciando algunos de sus signos distintivos: la reivindicación del espacio público, el efecto sorpresa y finalmente la voluntad de comunicar mensajes (y no realizar simplemente una decoración de exteriores). El artista tiene en cuenta el emplazamiento de sus murales, trata siempre de comunicarse con la sociedad que habita dichos espacios, buscando las singularidades de cada lugar, se trate de un paisaje urbano $o$ industrial.

Una visita en su blog nos afirma su compromiso y vocación. En la sección de DVD, a parte de algunos vídeos sobre el proceso de ejecución del graffiti sobre el muro (Speed Painting) ${ }^{6}$, podemos encontrar sus graffiti animados, entre los que destacamos Muto publicado en blogs desde 2008 - y el que realizó en colaboración con David Ellis titulado Combo o Big Bang Big Boom con banda sonora por Andrea Martignoni. 


\subsection{Los GIF publicitarios de Insa}

Otro formato de graffiti animado lo encontramos en los $\mathrm{GIF}^{7}$ del artista e ilustrador británico Insa. A diferencia de los graffiti animados de Blu, donde el artista narra una historia secuencial más o menos compleja desplegada dentro de un recorrido urbano siguiendo un guión fílmico-narrativo, los Gif-iti de Insa se ubican en un único espacio urbano acotado que actúa como soporte, generalmente un edificio o un muro de una calle de Londres, ejerciendo la función publicitaria en tipo banners que suelen ejercer los GIF.

El proyecto Gif-iti White Walls Project para Unit 44 (fig. 5) fue filmado en Inglaterra durante su producción ${ }^{8}$ y es un buen ejemplo del trabajo laborioso que comporta la realización de un graffiti animado.

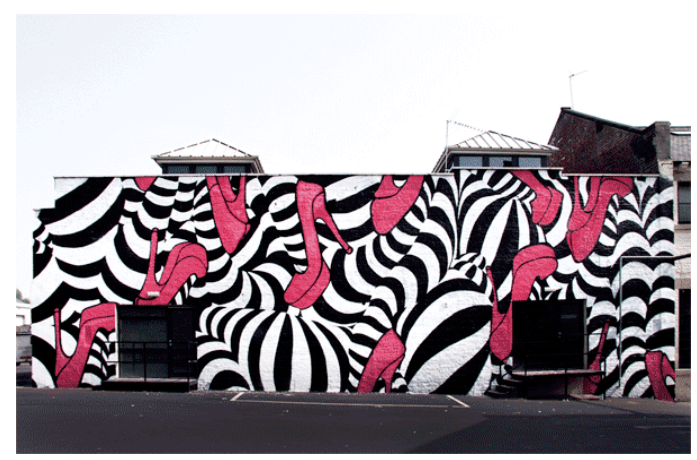

Fig.5 Insa, imagen del Gif-iti White Walls Project para Unit 44 (Newcastle, Inglaterra, 2011)

Uno de sus más recientes trabajos fue junto al artista Stanley Donwood en el edificio de XL Recordings de Los Ángeles. Reprodujo la portada del último álbum de la banda roquera 'Atoms for peace' titulado AMOK (2013). Insa pintó cuatro veces el exterior de XL Recordings en Los Ángeles (fig. 6a y 6b) para crear los cuadros de animación ${ }^{9}$.
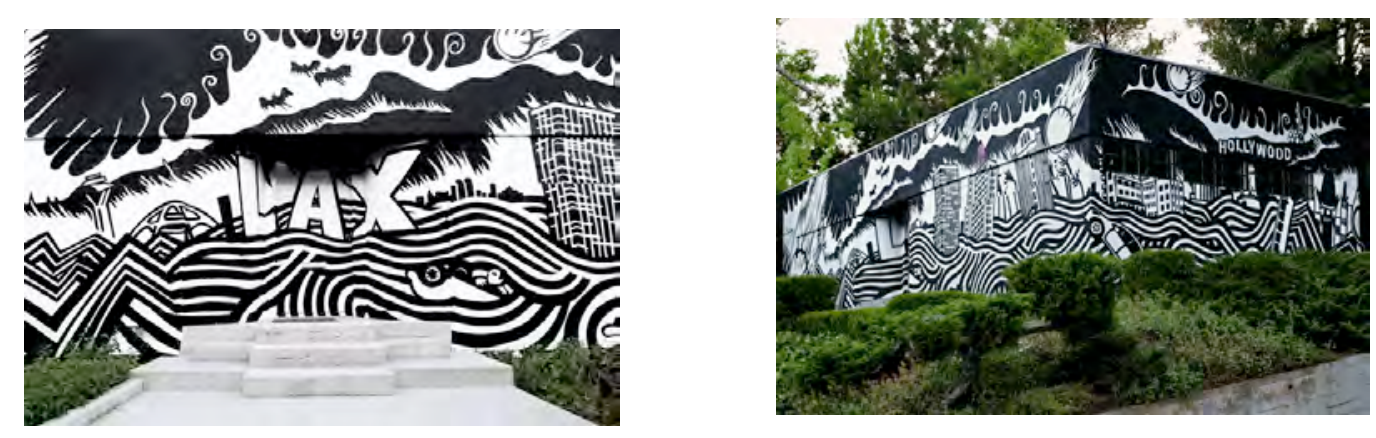

Fig. 6a y 6b. Vista exterior de XL Recordings (Los Ángeles, 2013)

\subsection{La 'limpieza urbana': El graffiti performance de Orion}

Otra modalidad procesal que consideramos que entraría dentro de la categoría graffiti animado, muy diferente a los que estamos comentando de Blu o Insa, es el graffiti 'inverso' realizado a partir de la 'limpieza urbana' del brasileño Alexandre Orion en el túnel Max Ferrer de Sao Paulo en el año 2006 y conocido como Ossario:Art less pollution (fig. 7a y 7b). Interesado por comunicar un mensaje de preocupación por la abundante contaminación de Sao Paulo, Orion recurrió a una técnica de expresión artística inusual y positiva, pero que de todas maneras resultó en la ira de las autoridades. Armado de un trapo y solvente, comenzó a limpiar las paredes del túnel cubiertas de una gruesa capa negra producto de las emisiones de los automóviles. Orion fue eliminando cuidadosamente la suciedad hasta dejar ver el luminoso color original de las paredes. Con cada pasada de su trapo iba "revelando" una macabra imagen: una serie de cráneos humanos dibujados en el contraste de la inmundicia y la limpieza. 

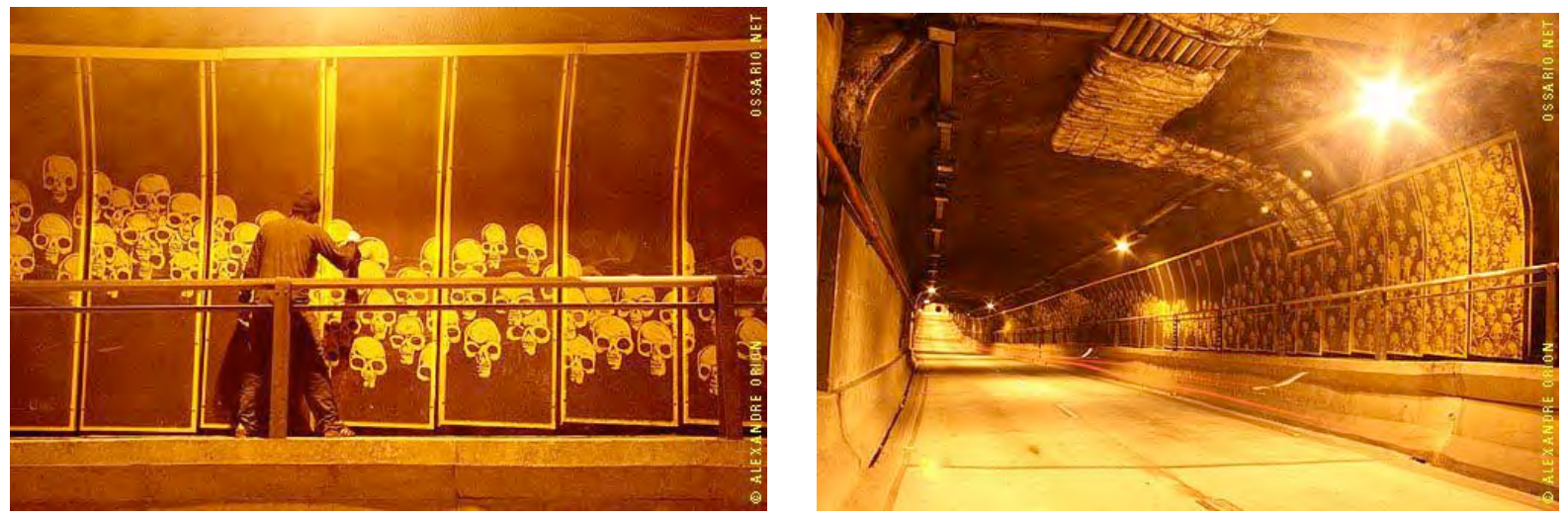

Fig. 7a y 7b. Dos imágenes de Ossario: Art less pollution de Orion (Sao Paulo, 2006)

La creación de Orion denunciaba lo que a menudo es invisible a nuestros ojos: la contaminación nos cubre y domina, sin darnos cuenta de que se trata de un manto de muerte. Paradójicamente, un acto de limpieza como el que realizó Orion para expresar sus inquietudes artísticas fue considerada un acto vandálico por las autoridades y destruido, tal como se narra en un extracto en el Diario Milenio, encontrado en el blog NewZion de Romei Eliseo:

"La supernatural visión desconcertó a las autoridades, que en un principio pensaron que las paredes habían sido pintadas con imágenes de cráneos, cuando en realidad habían sido parcialmente limpiadas. Aparentemente la diferencia de técnica no lo diferenciaba de vandalismo común, por lo que el ayuntamiento ordenó limpiar la pared para deshacerse de los cráneos. El hecho de perder tal obra de esta manera fue un hecho trágico, pero lo fue más aún el hecho de que sólo limpiaron la pared de los cráneos, evidenciando que consideraban este graffiti inverso más ofensivo que la inmundicia que normalmente cubría las paredes del túnel”10.

Consideramos este graffiti como animado en el sentido que es una obra efímera -sólo pudo contemplarse in situ circulando dentro del túnel antes de ser eliminado- visualizada en vídeo en su blog y que adquiere su sentido pleno como acto preformativo, que comprende desde la acción del artista para generar el mural hasta su destrucción con una limpieza del túnel por parte de la brigada de limpieza del ayuntamiento. Se genera una poética interesante entre la limpieza creativa del artista y la limpieza destructiva de las autoridades, considerando la acción un acto de vandalismo que hay que eliminar.

Nos gustaría comentar otra acción de graffiti aperformance que solo puede verse en la Web. Se trata del retrato que pintó en 1990 del artista estadounidense Denny Dent al guitarrista Jimi Hendrix al ritmo de la introducción de su álbum póstumo 'Jimi plays Monterey', en la Universidad de California. Dent prepara un espectáculo para realizar sus obras (coreografía, música, pinturas...) y generalmente la calle no es su plataforma de acción. En cambio el Speed Painting en Youtube ${ }^{11}$ del autor al que hacemos referencia pensamos que puede catalogarse como una modalidad de graffiti animado no por su resultado final (el retrato), ni por la obtención de una animación del mural pintado, sino por el proceso escénico de ejecución, el cual solo puede visionarse en Web. Esta acción performática, metaforseada, sobre el muro para llegar al retrato, es la que determina la animación.

\section{Graffiti digital interactivo}

Entendemos graffiti digital aquel graffiti cuyo objetivo es obtener una imagen digital que posteriormente será manipulada y formará parte de otra obra o requerirá de la colaboración del transeúnte para que tome sentido y/o se considere acabada. Por ejemplo, en el apartado anterior hemos visto como Orion trabaja con la mirada puesta en el resultado digital de sus graffiti. A caballo entre el Sreet Art, el arte multimedia y fotografía, este artista trabaja en espacios urbanos como plataforma base para su trabajo multimedia posterior. Por ejemplo, en su proyecto Metabiótica (2013) el artista presenta una serie de fotografías en las que la presencia del transeúnte forma parte de la obra y el graffiti toma sentido pleno una vez se contemplan las fotografías en la Web o en una sala de exposiciones (fig. 8a, 8 b y 8c). Indudablemente este trabajo es el resultado de la combinación de su pasión por la fotografía y el stencil: 

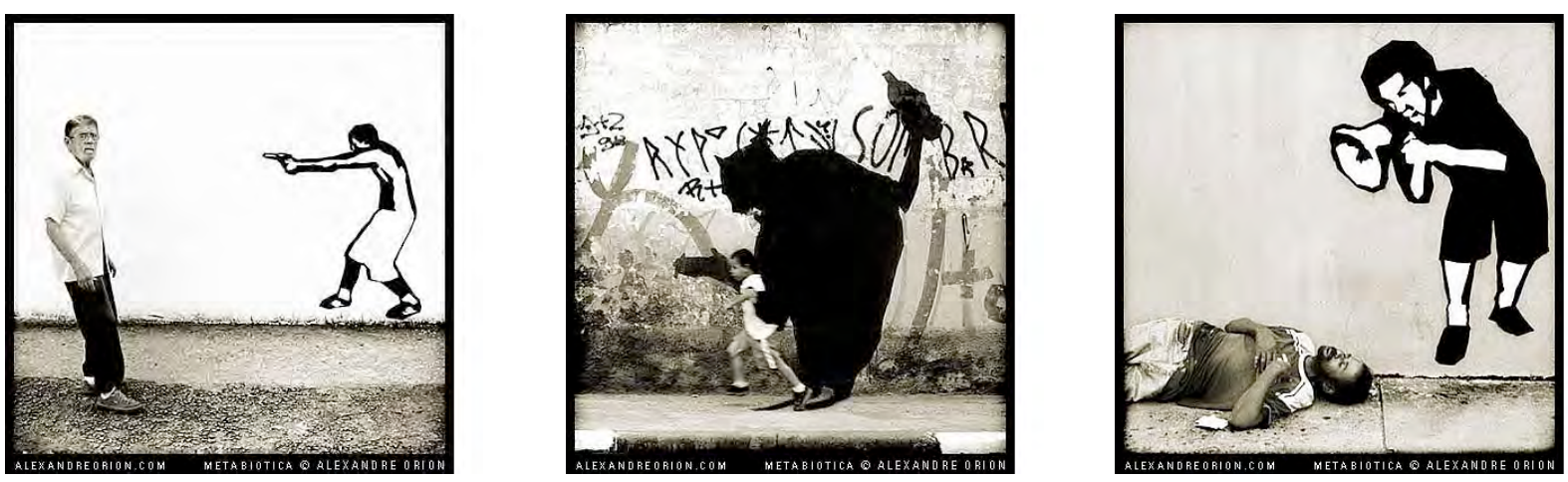

Fig. $8 a, 8 b$ y $8 c$. Tres fotografías del proyecto Metabióticos de Alexandre Orion.

Otro ejemplo de graffitis interactivos son las propuestas de Sweza. En ellas se requiere la interacción del peatón provisto de un lector QR de un smartphone para visualizar la obra que nos propone el artista. Por ejemplo, el proyecto QRadio ${ }^{12}$ (fig. 9) -que empezó en 2011 y fue conmemorado en un show en Berlín el otoño pasado- donde el artista muestra la figura de un radiocasete y espera a que un paseante se detenga y complete la pieza faltante de la obra: Si utiliza el lector QR de su teléfono, aparecerá un casete en la pantalla y comenzará a sonar música en las bocinas. Es un lindo gesto que vincula a la cultura de la música en casete con los artistas callejeros. La animación en este caso no es propiamente visual, pero sí acústica.

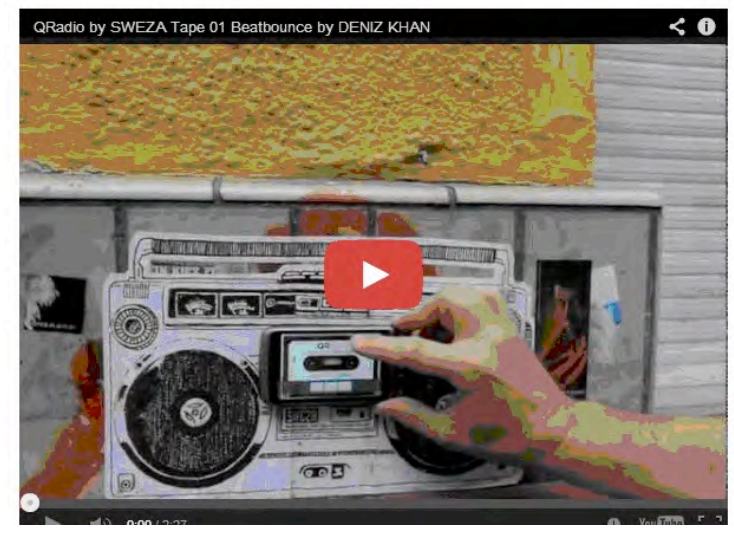

Fig.9 QRadio (Berlin, 2011). Proyecto interactivo de Sweza.

\section{Conclusiones}

Puede parecer paradójico que una acción artística que históricamente tiene su origen y sentido en la calle, termine colgada en la red y, en algunos casos, sin dejar huella tangible en el muro donde se produjo el graffiti animado. Pero si tenemos en cuenta las múltiples 'calles' de navegación en el ciberespacio, en ese intangible al que podemos acceder conectándonos en red desde un simple smartphone, comprendemos que el graffiti animado es un paso más hacia la democratización y globalización del arte urbano. El público de los graffiti animados son los 'transeúntes virtuales', que pueden navegar en calles a cualquier momento del día sin limitaciones territoriales, atmosféricas, temporales... Una distinción muy importante en relación a los graffiti tradicionales es que los transeúntes virtuales visitan la calle y contemplan el graffiti a voluntad, mientras que algunos transeúntes urbanos no adeptos a estas manifestaciones artísticas, tienen que consumirlo contra su voluntad, provocándoles, en algunos casos, reacciones adversas o desaprobadoras.

Como hemos podido constatar algunos artistas urbanos reúnen el arte callejero con la tecnología para llevar a cabo su proyecto. El espectador juega un rol activo en el sentido que puede decidir si contemplar o no la obra, ya que el acceso a web es voluntario. Incluso podemos encontrar propuestas artísticas, como la de Sweza, en las que el transeúnte es invitado a participar en ellas a través de su smartphone, para darle sentido y concluirla.

Indiscutiblemente nos encontramos ante un nuevo paradigma creativo dentro del Street Art y del Arte en general, ya que la práctica artística del graffiti animado ha contribuido a cambiar el mercado del arte. Por ejemplo, los murales y vídeos de Blu o Insa se ofrecen 
de forma gratuita por el espacio público de la ciudad y en la World Wide Web. Insa así lo comenta en una entrevista acerca de sus Gifiti en The Atlantic:

"Quería hacer obras que solo pudieran verse en la web. La libertad y la accesibilidad de Internet es lo que me inspira. La idea de hacer arte para web es que verdaderamente sea para todo el mundo y no se quede en galerías o en casas de coleccionistas privados" (Rosen, 2013: s.p.) $)^{13}$.

Decididos a ocupar una posición fuera del ámbito protegido del arte, algunos artistas de graffiti animado defienden una filosofía de código abierto en una persistente rebelión anárquica contra las convenciones del arte contemporáneo desde la perspectiva de la oficialidad cultural. Un claro exponente de ello es Alexandre Orion con sus acciones de 'limpieza urbana'. No cabe duda que aún sigue abierta la brecha entre los defensores y los detractores del graffiti ${ }^{14}$ y que la categorización por parte de algunos sectores oficiales de "acto vandálico" a erradicar en pro de la protección del patrimonio o preservación del espacio público no encajan en absoluto con el ejemplo que exponemos de Orion.

Nos gustaría concluir este artículo haciendo un énfasis especial en el papel relevante de las nuevas tecnologías en la Gráfica Urbana y en el Arte en general. No podríamos hablar de graffiti animado sin equipos digitales que lo posibilitan, e incluso, como ocurre en los proyectos de Swenza, los dispositivos móviles se convierten en una de las herramientas de creación para finalizar la obra. No cabe duda que hemos empezado un siglo donde la tecnología nos obliga a reflexionar el proceso creativo y a abordar las creaciones urbanas desde una nueva perspectiva impensable otrora. Por instinto de supervivencia los humanos nos aferrados a lo conocido, pero, afortunadamente, nuestra curiosidad y afán de superación nos empuja hacia lo novedoso y creador. En el graffiti animado se suman ambas actitudes, artesanía y tecnología, para ofrecernos obras de arte que nos hacen reflexionar, pensar y como no, disfrutar de un placer estético que tuvo y sigue teniendo sus detractores.

\section{NOTAS}

\footnotetext{
${ }^{1}$ Sobre las nuevas tipologías de graffiti/arte urbano son interesantes las publicaciones de Ganz (2005) y de Bou (2009).

${ }^{2}$ El zoótropo es una máquina estroboscópica creada en 1834 por William George Horner, compuesta por un tambor circular con unos cortes, a través de los cuales mira el espectador para que los dibujos dispuestos en tiras sobre el tambor, al girar, dan la ilusión de movimiento.

${ }^{3}$ Peter Mark Roger, en el año 1824, formuló la teoría de la sensación de movimiento generada en el cerebro del observado al ver una proyección de imágenes fijas registradas en continuidad sobre una película de celuloide a una frecuencia de 24 fotogramas. La sensación de movimiento se genera en el cerebro del observador gracias a la persistencia retiniana.

${ }^{4}$ Hyuro, (2013) In /Between2. Copenhagen. La artista urbana Hyuro ha creado este mural en Copenhagen con un alce en diferentes posiciones. Pareciera que el trabajo de Hyuro es ordinario pero se trata de una tira animada, quien observe el mural desde su auto en movimiento podrá ver caminar al alce a través de un bosque.

${ }^{5}$ El stop-motion es una técnica de animación que consiste en capturar fotografías consecutivas de un objeto moviéndolo un poco entre fotografía y fotografía de manera que visualizándolo rápidamente parece que el objeto se mueva. Generalmente se denominan animaciones de stop-motion a todas aquellas que no son realizadas ni con dibujos animados (también llamada animación tradicional 2D), ni tampoco creadas completamente dentro del ordenador (animación 3D), sino que han sido creadas tomando imágenes de la realidad. Así pues, el stop-motion se utiliza para producir movimientos animados de cualquier objeto, ya sea rígido como moldeable: juguetes, bloques de construcción... También se desarrollan animaciones en stop-motion muy interesantes con otros materiales, como la arena, los recortes de papel o los yesos sobre suelo y paredes. Podríamos definir esta manera de animar como la animación en estado puro, debido a que se construye el movimiento fotograma a fotograma, manipulando el objeto o el muñeco con las propias manos, de manera progresiva, hacia adelante, sin ninguna posibilidad de retroceso.

${ }^{6}$ Speed Painting en Youtube: Producciones audiovisuales realizadas por artistas utilizando distintos medios, tanto aquellos que son convencionales para la creación de obras plásticas como el dibujo y la pintura como los medios digitales que utilizan diferentes programas de creación y edición de imágenes. Estas producciones se graban durante todo el proceso de realización para ser editadas posteriormente acelerando la secuencia de grabación e incorporando audio para finalizar en breve período de tiempo.

${ }^{7}$ GIF (Compuserve GIF) Graphics Interchange Format. Es un formato gráfico utilizado ampliamente en la World Wide Web, tanto para imágenes como para animaciones. Insa denomina Gif-iti sus producciones.

${ }^{8}$ Lex van den Berghe publica en Photoshop.com del 13 febrero 2013 un vídeo del proceso de producción del Gif.iti White Walls Project además de una entrevista al artista que nos permite conocer su proceso de trabajo y su posicionamiento como artista dentro de la gráfica urbana.

${ }_{9}^{9}$ Para más información acerca del proyecto del Edificio XL Recordings ver el blog del Insa (Insaland 2009), recuperado el 15 de marzo 2014 de http://www.insaland.com/blog/insa-x-stanley-donwood-x-atoms-for-peace/

${ }^{10}$ La información la hemos recogido del blogger Romei Eliseo en NewZion. https://newzion.wordpress.com/?s=orion. Recuperado el 16 de febrero de 2014.
} 


\footnotetext{
${ }^{11}$ Para visionar el víedo de Denny Dent pintando el retrato de Jimi Hendrix al ritmo de la música del guitarrista de su álbum póstumo 'Jimi plays Monterey' hemos recurrido a Foxey Lady. Jimi Hendrix live painting by Denny Dent. 7 de diciembre del 2012. [Ref. 12 de febrero 2014 ] Disponible en Web: <https://www.youtube.com/watch?v=a73-zTst7ag>

${ }^{12}$ El proyecto QRadio de Sweza empezó en 2011 y fue conmemorado en un show en Berlín el otoño pasado, junto con otros trabajos de Sweza, como Graffyard. Ver vídeo recuperado de http://www.arteycallejero.com/2013/02/este-graffiti-interactivo-utiliza-uncodigo-qr-para-reproducir-musica-video/

${ }^{13}$ Rosen, Rebecca J. "The Paradox of GIF-iti: Street Art You Can See Only Online" http://www.theatlantic.com/technology/archive/2013/01/the-paradox-of-gif-iti-street-art-you-can-see-only-online/266943/ ${ }^{14}$ Acerca de la discusión entre los defensores y detractores del graffiti recomendamos la publicación de Figueroa-Saavedra (2007:116120).
}

\section{FUENTES REFERENCIALES}

BOU, Louis. Ultimate Street art. A celebration of graffiti and urban art. Barcelona: IJB Ediciones, 2009. 478 p. ISBN: 9788496823846

FIGUEROA-SAAVEDRA, Fernando. "Estética popular y espacio urbano: El papel del graffiti, la gráfica y las intervenciones de calle en la configuración de la personalidad de barrio". Revista de Dialectología y Tradiciones Populares, 2007, enero-junio, LXII (1), p.111-144.

GANZ, Nicholas. Graffiti. Arte urbano de los cinco continentes. Barcelona: Editorial Gustavo Gili, 2006. 375 p. ISBN-13: 978-84-2521954-2, ISBN: 84-252-1954-X

Webgrafía

ARTE CALLEJERO. Este graffiti interactivo utiliza un código $Q R$ para reproducir música [en línea]. Powered by WordPress, Endless \& Sneek. 19 de febrero 2014 [Ref. de 21 de marzo del 2014]. Disponible en Web: <http://www.arteycallejero.com/2013/02/este-graffiti-interactivo-utiliza-un-codigo-qr-para-reproducir-musica-video/>.

BC 2.0. ¿Y si lo que haces es limpiar?. [en línea]. 19 de mayo 2008 [Ref. de 15 de marzo del 2015]. Disponible en Web: <http://bibliocriptana.wordpress.com/2008/05/19/\%C2\%BFy-si-lo-que-haces-es-limpiar/>.

BLU. Muto \& Big Bang Big Boom. [en línea]. 2008 \& 2010 [Ref. de 2 de febrero del 2015]. Disponible en Web: <http://blublu.org/sito/video/muto.html>.

BLU. Combo a collaborative Animation by Blu and David Ellis. [en línea]. Studio Cromie: Grottaglie, Southern Italy.Fame Festival, 2009. [Ref. de 21 de febrero del 2015]. Disponible en Web: <http://vimeo.com/6555161>.

FOXEY LADY. Jimi Hendrix live painting by Denny Dent. 7 de diciembre del 2012. [Ref. 12 de febrero 2014 ] Disponible en Web: <https://www.youtube.com/watch?v=a73-zTst7ag $>$.

HYURO. Layers [en línea]. Copenhagen 2013. [Ref. de 10 de enero del 2015]. Disponible en Web: <http://www.hyuro.es/project/\%C2\%A8inbetween\%C2\%A8copenhagen-2013/>.

HYURO, (2013). In /Between2. [en línea]. 2011. [Ref. de 10 de enero del 2015]. Disponible en Web: <http://www.hyuro.es/project/\%C2\%A8layers\%C2\%A8-2011/>.

INSA. Insa x Staley Donwood x Atoms for peace. [en línea]. Edificio XL Recordings, Los Ángeles. Insalad 2009. [Ref. de 8 de marzo del 2015]. Disponible en Web: <http://www.insaland.com/blog/insa-x-stanley-donwood-x-atoms-for-peace/>.

JOBSON, Christopher. The animated GIF-iti of Insa. [en línea]. Colossal. Art, desing and visual culture. 10 de diciembre de 2010. [Ref. de 14 enero del 2015]. Disponible en Web: <http://www.thisiscolossal.com/2012/12/the-animated-gif-iti-of-insa/>.

ORION, Alexandre. (22/08/2006) Ossario: Art less pollution. [en línea]. 22 de agosto del 2006. [Ref. de 14 diciembre del 2014]. Disponible en Web: <http://www.alexandreorion.com/ossario/images.html>. 
ORION, Alexandre. (2004). Metabiótics. [en línea]. 22 de agosto del 2006. [Ref. de 9 de febrero del 2015]. Disponible en Web: $<$ http://www.alexandreorion.com/meta/>.

ROMEL, Eliseo. Recomendación: Alexandre Orion. Graffiti. NewZion by Romel Eliseo Luis Bernardo. 2 de diciembre de 2008 . [Ref. de 14 febrero del 2015]. Disponible en Web: <http://newzion.wordpress.com/2008/08/29/recomendacion-alexandre-orion-graffiti/>.

ROSEN, Rebeca J. (8/01/2013). "The Paradox of GIF-iti: Street Art You Can See Only Online” [electronic version]. The Atlantic. Atlantic Media Company: US and Canada. de enero del 2013. [Ref. de 14 marzo del 2015]. Disponible en Web: <http://www.theatlantic.com/technology/archive/2013/01/the-paradox-of-gif-iti-street-art-you-can-see-only-online/266943/>.

VAN DEN BERGHE, Lex. Graffiti Artist INSA Discusses Inspiration, Motivation and Incarceration. PhotoShop.com blog. 13 de febrero de 2013. [Ref. de 14 enero del 2015]. Disponible en Web: <http://blogs.adobe.com/photoshopdotcom/2013/02/graffiti-artist-insadiscusses-inspiration-motivation-and-incarceration.html>. 